and inaccurate in establishing long-distance contacts around our own planet. The revolution in communication and computing is a phenomenon of the past few decades. There have been so many dramatic changes in the way we communicate and travel worldwide that modern life has been profoundly affected.

The impetus behind the changes has been 'globalization'; a society has emerged which has an increasing need to communicate throughout the world, at any time of day or night; this is a society that can no longer operate on a $8 \mathrm{am}-5 \mathrm{pm}$ day. By enabling this society to be online 24 hours a day, says Leon Kreitzman, time has been expanded.

Scientists know this only too well. Trying to collaborate with a colleague based in California while in Europe, or arguing back and forth across the Atlantic with a scornful editor over a manuscript were difficult tasks only a few years ago. Time is even more pertinent to the business world, in which ignoring a 24-hour timescale would be financial suicide.

People adjust immediately to new devices, sometimes becoming conditioned to them without even knowing it. We have almost no recollection of how we functioned before faxes and e-mail, and contemporary society would clearly have a hard time functioning without these gadgets.

This is the core of Kreitzman's book, which is entertaining and easy to read, but also refined and comprehensive. Kreitzman ranges from business to informatics, from circadian biology to social science and working regulations. The 24 -hour society is most obviously represented by cities in Europe and the United States, but shopping and leisure are also available around the clock in Asia. The demand for flexible timing for these activities has developed in a growing proportion of the population. Of course, this is distinctive of a certain type of social economy, as Karl Marx (cited by Kreitzman) rightly reasoned: "labour during 24 hours of the day is the inherent tendency of the capitalist production."

Working mothers are a particularly apposite case, as most of them need to have a more stringent organization of their time because a high proportion of partners still do not help with housekeeping and child care. They are a group of people who can greatly benefit from a society that allows flexible use of facilities and services.

Another interesting example is the tourism industry, which has grown dramatically in the past couple of decades. Today tourism is global; in the 1980s it took over from oil as the world's largest industry, and now today it accounts for 10 per cent of the world's gross national product. People like to travel far afield, and as their time is limited, they want to have services, tourist attractions, museums, shopping and dining available at all times, everywhere they go.

Humans, distinct from all other animals, have had their circadian rhythms modified by social habits, electric light, television and international travel. Our natural sleep/wake cycle, as well as our endogenous biological clock, are continuously challenged by external stimuli that have nothing to do with the natural day/night astronomical cycle. Kreitzman gives a remarkably simple but clear (and correct) synthesis of our present knowledge of the biological clock. His hope is that "once we can control our rhythms many of the objections to shift-working and to the 24 Hour Society will fall away". The intrinsic danger of such thoughts is the possibility of biological control over people by society. But Kreitzman is careful to emphasize that advantages of the 24-hour society should not be "achieved by the exploitation of the health and safety of groups in the population".

So, is the 24-hour society some kind of present/future positive condition, or just a nightmare in which the Western world is caught up? Our parents say that it was so much better in their day, when the pace of life was slower and they had more time to enjoy valuable moments. Today it is difficult to have a normal conversation with a friend or colleague without being interrupted by a beep or a ring, and it does seem to many that enjoyable moments are becoming rarer. But I feel that Kreitzman is right; it is just a matter of getting adjusted to new rules and redefining temporal relationships. Then we will gradually, but continuously, learn to enjoy a different timing for the important things in our lives, and by the same token possibly gain time.

Paolo Sassone-Corsi is at the Institut de Génétique et de Biologie Moléculaire et Cellulaire, BP 163,

67404 Illkirch, Strasbourg, France.

\section{. Know thyself genetically}

\section{Genome: The Autobiography of a} Species in 23 Chapters

by Matt Ridley

Fourth Estate: 1999.752 pp. $£ 18.99, \$ 26$

\section{W. F. Bodmer}

Genetics, I believe, will stand alongside computing and nuclear physics as one of the outstanding areas of development by which this century will be remembered. The century started precisely with the rediscovery of Mendelism and it will finish with a first draft of the complete DNA sequence of the human genome. That remarkable catalogue of the human genes, ordered along the chromosomes to give us the Book of Man, will form the basis of most future biological and biochemical investigations of humans. The end of the Human Genome Project is the beginning of the real genetics of mankind. And this is the substantial challenge for understanding over the next century or more.

By combining the power of molecular genetics with classical population genetics and quantitative analysis, new approaches have been devised, not only for the 'positional' cloning of Mendelian traits whose biochemical basis was totally unknown, but also for identifying genes that contribute to the inherited susceptibility to multifactorial traits and diseases. Genes associated with nearly every Mendelian disease have been cloned, however rare the disease. But recall the great physician William Harvey, who urged us to treasure our exceptions, from which, as we now know, so much can be learnt. There is an exciting story to be told about genetics in the genomic era, but that is not to be found in Matt Ridley's book.

His title leads to the expectation that these exciting developments in genetics will be revealed to the general reader. However, in the preface we are told that "this is not a book about the human genome project", but instead "a book about what the project has found". The book is based on an intriguing idea, namely, to progress through the chromosomes chapter by chapter, using in each an example to illustrate what the genome reveals when it is properly read and interpreted. Ridley, a professional science writer and journalist, has, however, followed a common journalist's pathway and selected a collection of topics that he presumes will interest the reader whether or not they are relevant to his professed goal. Too many of these topics, such as sexual evolution, IQ, personality, stress and its relationship to immunity, ageing, memory and even, finally, free will, are simply not yet ready to yield to modern genetic approaches. They are mostly a basis for largely unsubstantiated speculation described in a way that could have been written without any reference to what the genome has to tell us.

Chromosome 1, the largest, is, according to Ridley, apparently empty, although a discussion of the rhesus blood groups might have been of interest. Chromosome 2 is used only as a vehicle for comparing Homo sapiens with the chimpanzee, the first of many "mind boggling" comparisons, in this case because of Ridley's apparent surprise that it may take only a relatively small number of differences in the DNA code to distinguish man from chimpanzees. Huntington's disease occupies chromosome 4. Certainly, it is an interesting story, but hardly, as the author claims, the most talked about genetic disease.

Given my own long-standing involvement with the HLA system and the genetics 


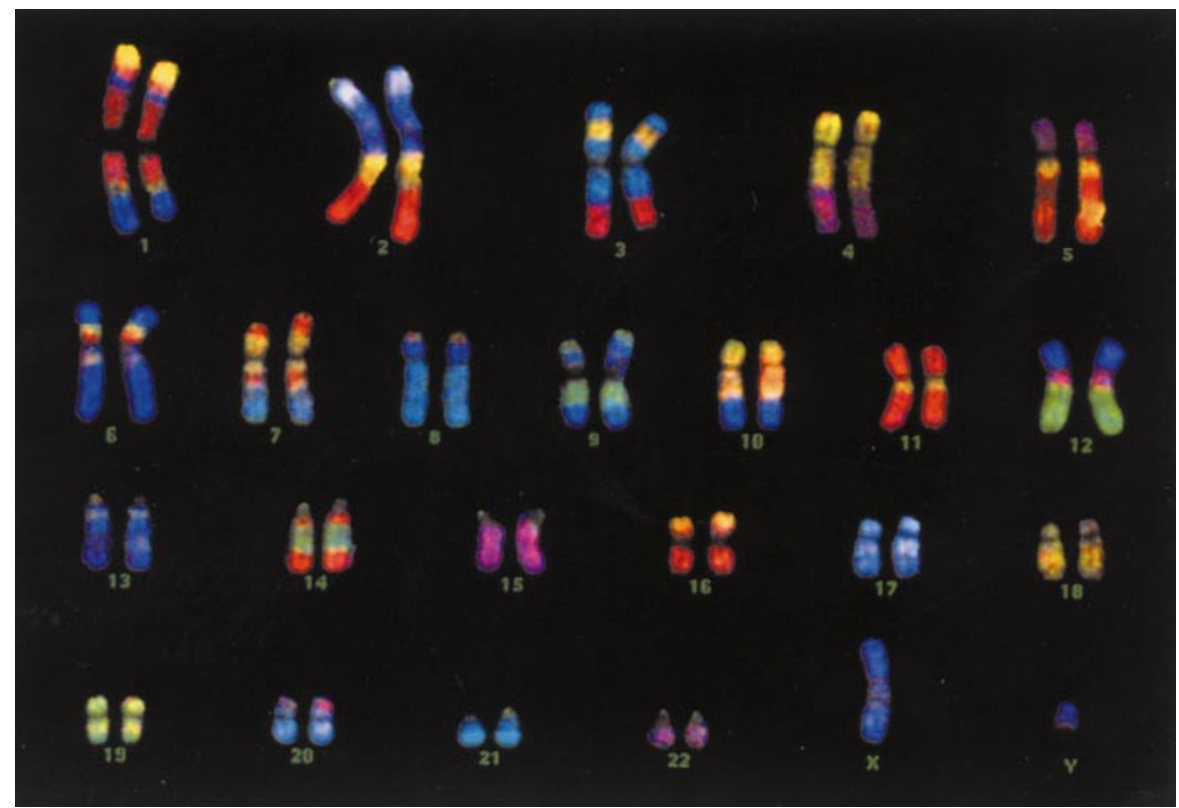

Chapter and verse: the entire contents of the 23 human chromosomes should soon be known.

of the immune response, such topics would have been my natural choice for chromosome 6. But immunology, in spite of its enormous interest and dramatic development, hardly gets a mention, even in the discussion of asthma, and the only reference to the HLA system is in relation to the rather questionable data on mating preferences. Ridley's chromosome 6 is devoted to the somewhat flimsy evidence for a gene with a possible influence on IQ.

There are some good chapters. The relationship between the apoE lipoprotein gene and Alzheimer's disease is well told and the chapter on BSE is also good. Ridley even mentions James Parry, the geneticist in Oxford whose sheep pedigrees told the correct story about scrapie, as he explained to me when I first came to Oxford in 1970, and which no one believed. A good chapter on eugenics is seriously marred by the fact that it draws the analogy between screening for Down's syndrome and Nazism. Even negative eugenics is hardly applicable to Down's syndrome, and the importance of doing genetic screening only if benefit can be derived from it is hardly mentioned.

Historical treatments of scientific discoveries are a good vehicle for presenting the underlying science, but not when they are as abbreviated and distorted as they often are in Genome. There were, for example, several co-discoverers of the $p 53$ gene; and the molecular biology of prions was uncovered by Charles Weissmann and his colleagues. The story of Gregor Mendel's discoveries is described as though they appeared from nowhere, and ignores the evidence that they were stimulated by his abbot's interest in uncovering the basis for the animal and plant breeding used in the monastery's farms. It was the theoretical physicist
George Gamow, not Francis Crick, who first suggested codes relating DNA to protein. I still remember when, as a young mathematical geneticist, I sought Crick's advice about problems I might investigate in molecular biology, and he suggested that I explore the mathematics of overlapping codes. Fortunately and correctly, I did not see how my mathematics could help to provide a solution to the coding problem, which eventually came entirely from experimental approaches.

Style is, I suppose, a matter of personal preference. "Now I tell you again Dear Reader" somehow does not, to my mind, match the topic of 'genome'. Suddenly, towards the middle of the book, we are told "the human genome project is founded upon a fallacy"! He has clearly not yet explained the importance of human variation, which underlies any explanation, for example, of the balance between nature and nurture. Perhaps it is this he is referring to when he says, "the tension between universal characteristics of the human race and particular features of individuals is what the genome is all about". There is also the occasional strange, throwaway sentence: "But then judges were never very good at science" seems a remarkably injudicious comment, and I wonder on what basis he makes this extraordinary suggestion.

Ridley has written well in the past on evolutionary topics, and is clearly capable of writing in a stimulating way for the general reader. Perhaps in future he would do best to stick to topics involving evolutionary ideas, where he is most at home. If this book kindles an interest in the genome and what can be found out using modern genetic approaches, then perhaps it is doing a service. But if you want a serious and challenging discussion of what genetics and the genome can tell us about humans, I am afraid you must look elsewhere.

Walter Bodmer is at the Cancer and Immunogenetics Laboratory, Imperial Cancer Research Fund, Institute of Molecular Medicine, Oxford OX3 9DS, UK.

\section{Darwin's evolution}

\section{Almost Like a Whale: The Origin of Species, Updated \\ by Steve Jones \\ Doubleday: 1999. 402 pp. $£ 20$ \\ Mark Pagel}

Gilbert White, writing in 1773 in his Natural History and Antiquities of Selborne, understood why owls have unusually "soft and pliant" feathers on the tips of their wings, but he could not begin to comprehend why "some females of the brute creation ... devour their young", adding "I leave [this] to abler philosophers than myself to determine". Writing a century later, a biologist gave the answer, "these practices appear to have originated in savages recognising the difficulty, or rather the impossibility of supporting all the infants that are born".

The biologist was Charles Darwin, whose Origin of Species had by the time of this quote already earned him fame and opprobrium in various quarters. The reason was not that Darwin could explain better than others the functions of the diverse traits and characteristics of animals, but that he had offered a mechanistic account of how animals, including humans, come by those traits. That mechanism he called 'natural selection', and so radical were Darwin's views that much of the Origin can be seen as a highly selfconscious defence of his claims for its near-exclusive role in shaping life. Every page carries a sense of Darwin's disquiet that, at least for the reader, some insuperable challenge to natural selection will arise: Darwin repeatedly reminds us of the truth of "my theory", or the plausibility of "my account".

By all reasonable measures, the theory has given a good account of itself. Academic journals, books, newspapers, radio and television brim with 'darwinian' (this journal now insists on the lower case in the adjective) investigations of this or that, and they are not limited to biology. Economics, politics, philosophy, linguistics, psychology, medicine and other fields have succumbed to the darwinian juggernaut. Novelists are asked to debate its merits. Sophistication shows up where least expected: the Kansas Board of Education creationists who recently banned Darwin from Kansas schools accept the reality of microevolution (evolution within species); they just don't like macroevolution 